\title{
Prolonged neonatal myocardial preservation with a highly buffered low-calcium solution
}

\begin{abstract}
Optimal methods of myocardial preservation remain controversial in the neonate. This study compared prolonged hypothermic storage of neonatal hearts with modified University of Wisconsin solution (group I) with a solution formulated to promote anaerobic glycolysis by providing proton buffering with histidine $(100 \mathrm{mmol} / \mathrm{L})$ and exogenous glucose and insulin (group II). Hearts from piglets aged 3 to 5 days were given a single dose of either solution $(n=6$ each), subjected to 20 hours of global ischemia at $4^{\circ} \mathrm{C}$, and reperfused with an erythrocyte-enhanced perfusate in an isovolumic Langendorff preparation. After 1 hour of reperfusion, in comparison with hearts preserved with University of Wisconsin solution, those in group II demonstrated (mean \pm standard error of the mean) greater left ventricular developed pressure $(101 \pm 7$ versus $62 \pm 9 \mathrm{~mm} \mathrm{Hg}, p<0.01)$ and the first derivative of left ventricular pressure $\left(816 \pm 23\right.$ versus $\left.614 \pm 69 \mathrm{~mm} \mathrm{Hg} \cdot \sec ^{-1}, p<0.05\right)$. Diastolic indices were reduced to a similar degree in the two groups. Myocardial oxygen consumption was significantly greater $\left(38.8 \pm 2.4\right.$ versus $11.8 \pm 2.4 \mu \mathrm{l}$ oxygen $\left.\cdot \min \cdot \mathrm{g}^{-1}, \mathrm{p}<0.01\right)$ in group II hearts. Group I hearts vasoconstricted $(6 \%$ increase in coronary vascular resistance) in response to an intracoronary infusion of acetylcholine ( $\left.20 \mathrm{nmol} \cdot \mathrm{min}^{-1}\right)$; in contrast, acetylcholine produced coronary dilation in group II hearts $(5 \%$ decrease in coronary resistance, $p<0.02)$ that was similar to that observed in nonischemic control hearts. These results demonstrate enhanced preservation of myocardial contractility, oxidative metabolism, and vascular function in neonatal hearts provided by a solution designed to buffer protons and promote anaerobic glycolysis during ischemia. (J THORAC CaRdiovasC SuRg 1994;108:772-9)
\end{abstract}

Francis X. McGowan, Jr., MD, ${ }^{a}$ Hung Cao-Danh, PhD, ${ }^{\mathrm{b}}$ Koh Takeuchi, MD,

Peter J. Davis, MD, ${ }^{\mathrm{a}}$ and Pedro J. del Nido, MD, ${ }^{\mathrm{b}}$ Pittsburgh, Pa.

I mprovements in surgical techniques, immunosuppression, and perioperative care have enabled heart transplantation to become an effective therapy for severe left ventricular (LV) failure in both children and adults, as well as for lethal congenital defects such as hypoplastic left heart syndrome. In addition to an inadequate supply

From the Departments of Anesthesiology/CCM, ${ }^{a}$ Pediatrics, ${ }^{a}$ and Cardiothoracic Surgery, ${ }^{b}$ University of Pittsburgh School of Medicine, Pittsburgh, Pa.

Supported in part by National Institutes of Health grant R29-HL46207 (Dr. del Nido), the International Anesthesia Research Society B.B. Sankey Anesthesia Advancement Award (Dr. McGowan), and Children's Hospital of Pittsburgh.

Received for publication Dec. 12, 1993.

Accepted for publication May 2, 1994.

Address for reprints: Francis X. McGowan, Jr., MD, Children's Hospital of Pittsburgh, Department of Anesthesiology, 3705 Fifth Ave. at DeSoto St., Pittsburgh, PA 15213-2583.

Copyright $\odot 1994$ by Mosby-Year Book, Inc.

$0022: 5223 / 94 \$ 3.00+0 \quad 12 / 1 / 57437$ of donor organs, a major limitation is the relatively short period of ischemic storage that will allow explanted hearts to recover adequate function. Cold cardioplegic arrest in situ followed by hypothermic storage is the most common method of preservation used clinically.! A substantial variety of widely different cardioplegic and preservation solutions have been used. ${ }^{2-4}$ In the absence of continuous perfusion techniques, 4 to 6 hours remains the accepted duration of cold ischemic preservation that can be followed by successful reimplantation. $1,2,5,6$

The relative vulnerability of the neonatal myocardium to ischemia, as compared with the adult myocardium, remains controversial. ${ }^{7-10}$ Developmental differences in metabolic pathways, ${ }^{11-13}$ contractile proteins, ${ }^{14-16}$ and calcium regulation ${ }^{16-18}$ have been identified in the neonate. The enhanced glycolytic potential of the newborn infant has received particular attention. ${ }^{12,13,19,20}$ Increased tolerance of the neonatal myocardium to ischemia or hypoxia, or both, has been explained by 
some $e^{7,19-23}$ on the basis of increased anaerobic glycolysis. Alternatively, increased myocardial lactate production by the neonate during ischemia has been noted and suggested to contribute to myocardial injury. ${ }^{23,24}$ In addition, ischemic contracture occurs at higher myocardial adenosine triphosphate (ATP) concentrations in the neonate. ${ }^{22}$ The utility of various myocardial preservation regimens in infants is equally uncertain. $7,8,10,24-27$ These issues are particularly relevant to prolonged ischemia and long-term myocardial preservation. Anaerobic glycolysis is the only metabolic pathway active during ischemia that can produce high-energy phosphates and oxidize the reduced form of nicotinamide-adenine dinucleotide. In adult models, using histidine as a buffer during ischemia to remove $\mathrm{H}^{+}$has been shown to promote anaerobic glycolysis, preserve myocardial high-energy phosphate concentrations, and result in improved recovery of contractile function. ${ }^{28-30}$ The hypothesis for the present experiments was that the effects of proton buffering and augmented anaerobic glycolysis would be especially pronounced in the neonatal heart. This hypothesis was tested with a cardioplegic solution containing histidine, glucose as a substrate for anaerobic glycolysis, and insulin to promote glucose uptake. The solution also contained low sodium and calcium concentrations, as well as lidocaine, to reduce cation accumulation during ischemia. The effects of myocardial preservation with this solution were compared with those obtained with modified University of Wisconsin (UW) solution in a clinically relevant model of hypothermic storage for 20 hours at $4^{\circ} \mathrm{C}$ in isolated neonatal pig hearts. Hearts were reperfused with red blood cell-enhanced perfusate, ${ }^{31}$ and effects on systolic and diastolic function, myocardial oxygen consumption, tissue water accumulation, and coronary vascular response to acetylcholine were determined.

\section{Methods}

Myocardial preservation. All experiments were performed with the approval of the institutional Animal Care and Use Committee and conformed to the Helsinki Declaration. Piglets aged 3 to 5 days were obtained from a commercial breeder. General anesthesia was induced with sodium pentobarbital ( 25 to $30 \mathrm{mg} / \mathrm{kg}$ intraperitoneally), a tracheotomy performed, and mechanical ventilation begun. A polyethylene catheter was placed via the right carotid artery into the ascending aorta immediately proximal to the aortic valve. After anticoagulation with heparin (1000 U intravenously), the aorta was crossclamped, the inferior vena cava transected, and $60 \mathrm{ml}$ of $4^{\circ} \mathrm{C}$ preservation solution administered over 2 minutes via the aortic catheter. The heart was then rapidly excised by transection of the pulmonary hilus, superior vena cava, and great vessels and was placed into $4^{\circ} \mathrm{C}$ preservation solution. The aorta was cannulated, an additional $20 \mathrm{ml}$ of solution was administered over 1 minute through the aortic cannula, and the heart was stored in preservation solution for 20 hours at $4^{\circ} \mathrm{C}$. This second infusion was done to ensure removal of any donor blood that may have entered the coronary circulation during the harvesting process.

Isolated heart preparation. At the completion of the storage period, retrograde perfusion with a red blood cell-enhanced perfusate was begun with a modified Langendorff apparatus. Details of the preparation have been described elsewhere. ${ }^{31}$ The pulmonary artery was cannulated and a latex balloon passed into the $L V$ via a small incision in the left atrium. A ligature was placed around the left atrium so as to close the atrial incision, maintain balloon position within the LV, and prevent shunting across a patent foramen ovale. With this arrangement, pulmonary arterial effluent is composed solely of coronary venous blood. Balloons of different sizes were prepared, and for each experiment balloon volume was chosen to be greater than estimated LV volume (the estimate was based on pilot experiments and measured external LV dimensions). The balloon was connected to a micromanometry catheter (Millar Instruments, Inc. Houston, Tex.) via a short length of polyethylene tubing. A calibrated syringe was used to vary balloon volume and thus LV end-diastolic pressure. The isolated heart was enclosed in a close-fitting water jacket which maintained right ventricular temperature at $36.5^{\circ} \pm 1.0^{\circ} \mathrm{C}$. Aortic pressure was measured with an in-line transducer.

Arterial gas exchange was carefully controlled with a mixture of $95 \%$ oxygen and $5 \%$ carbon dioxide passed through the perfusate. Aortic blood gas tensions were determined frequently; oxygen tension and carbon dioxide tension were maintained at 300 to 350 torr and 30 to 40 torr, respectively, and $\mathrm{pH}$ at 7.38 to 7.45. Perfusate temperature was measured continuously and maintained at $36.5^{\circ} \pm 0.5^{\circ} \mathrm{C}$ with a heat exchanger.

Perfusate. A red cell-enhanced Krebs-Henseleit buffer solution was used as the perfusion medium. Human erythrocytes were filtered through a $40 \mu \mathrm{m}$ blood filter (Pall Biomedical Products, East Hills, N.Y.), washed thrice with $0.9 \%$ sodium chloride, and then twice with a solution consisting of $2 \%$ bovine serum albumin (Cohn fraction V; endotoxin-free) in Krebs-Henseleit buffer. The washed erythrocytes were added to filtered, modified Krebs-Henseleit solution containing $2 \%$ bovine serum albumin, glucose $5 \mathrm{mmol} / \mathrm{L}$, palmitate about 0.5 $\mathrm{mmol} / \mathrm{L}$, and the following in millimoles per liter: $\mathrm{NaCl}, 118$; $\mathrm{KCl}, 4.7 ; \mathrm{MgSO}_{4}, 2.4 ; \mathrm{KH}_{2} \mathrm{PO}_{4}, 1.2 ; \mathrm{NaHCO}_{3}, 25$; and $\mathrm{CaCl}_{2}$, 2.4. A final hematocrit value of $22 \%$ to $25 \%$, comparable with that of newborn piglets, was used. Insulin (porcine) was added to produce a final concentration of $25 \mu \mathrm{U} / \mathrm{ml}$, equivalent to that found in fasted piglets in vivo (unpublished observation). A nonrecirculating mode of perfusion was used to avoid contamination from metabolites released by the heart. A $20 \mu \mathrm{m}$ filter (Statlabs, Nashville, Tenn.) was placed in-line in the perfusion apparatus to remove microaggregates.

Reperfusion protocol. At the end of the ischemic interval, reperfusion was begun by perfusion pump at $0.5 \mathrm{ml} / \mathrm{min}$ per gram total heart weight and increased over the ensuing $10 \mathrm{~min}$ utes to $2.0 \mathrm{ml} / \mathrm{min}$ per gram. This rate exceeds that required for adequate delivery of oxygen and substrate. ${ }^{31}$ Precise control of coronary flow facilitated accurate measurement of myocardial oxygen consumption; additionally, changes in coronary vascular resistance were directly reflected by changes in coronary perfusion pressure. At 5 to 7 minutes of reperfusion, ventricular fibrillation (if present) was terminated with 5 watt-seconds of 
A

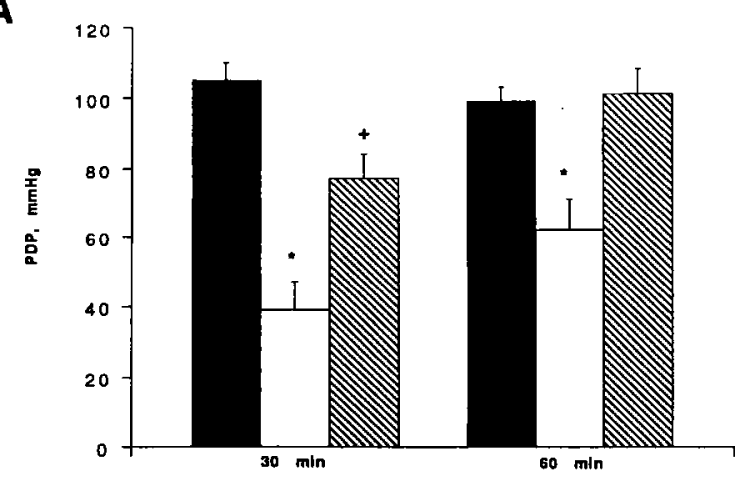

B

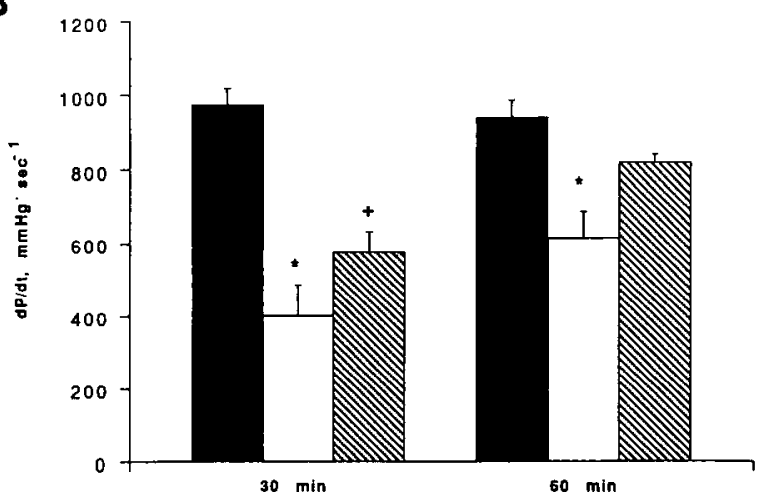

Fig. 1. Effect of modified UW (open bar) and histidine-buffered (hatched bar) solution on recovery of systolic function. Solid bars indicate values in the control preparation. A, Peak developed LV pressure $(P D P)$. B, First derivative of LV pressure rise $(d P / d t)$. Data shown are mean \pm standard error of the mean. Times indicated are during reperfusion after 20 hours of preservation at $4^{\circ} \mathrm{C} .{ }^{*} p<0.02$ versus control. ${ }^{+} p<0.05$ versus control.

direct current, and atrial pacing was begun at 150 beats $/ \mathrm{min}$ (approximately 20\% above intrinsic rate). LV pressure was measured with the latex balloon empty for the first 15 minutes of reperfusion; subsequently, LV end-diastolic pressure was adjusted to $5 \mathrm{~cm} \mathrm{H}_{2} \mathrm{O}$ by manipulating balloon volume. Ventricular function curves, myocardial oxygen consumption, and coronary vascular resistance were assessed at 30 and 60 minutes of reperfusion.

Control hearts. For purposes of comparison, hearts from six piglets aged 3 to 5 days were studied under identical conditions in the absence of ischemic preservation. After anesthesia and anticoagulation as described earlier, hearts were rapidly excised, the aorta cannulated, and retrograde perfusion begun (within 1 minute) with the Langendorff column. After an initial 30-minute stabilization period, coronary flow was controlled at $2 \mathrm{ml} / \mathrm{min}$ per gram total heart weight. Measurements as described were made at 30 and 60 minutes of perfusion.

Assessment of mechanical function. LV end-diastolic pressures were adjusted by changing LV balloon volume with a cal- ibrated syringe. Peak LV developed pressure, the first derivative of $\mathrm{LV}$ pressure ( $\mathrm{dP} / \mathrm{dt}_{\max }$ ), LV end-diastolic pressure, and aortic perfusion pressure were recorded continuously.

Peak negative $\mathrm{dP} / \mathrm{dt}$ was used as one index of diastolic compliance. The relationship of LV end-diastolic pressure to volume was also assessed as described by Glantz and Parmley. ${ }^{32}$ Diastolic pressure-volume data were entered into the equation $\mathrm{P}=\mathrm{Be}^{\mathrm{kV}}+\mathrm{C}$; chamber stiffness was calculated from the slope of this relationship at an end-diastolic pressure of $5 \mathrm{~cm} \mathrm{H}_{2} \mathrm{O}$.

Coronary vascular resistance and myocardial oxygen consumption. Coronary flow was measured by timed collection of the pulmonary arterial effluent. Simultaneous samples were obtained anaerobically from aortic and pulmonary artery sites for blood gas measurements. Oxygen content was measured directly by co-oximeter. Myocardial oxygen consumption was calculated as the product of coronary flow and arteriovenous oxygen difference. Lactate content of coronary arterial and venous blood was measured enzymatically. ${ }^{33}$

Coronary vascular resistance, defined as coronary perfusion pressure divided by coronary flow, was measured. However, because during the experiments coronary flow was maintained constant, only coronary perfusion pressure will be reported. At 60 minutes of reperfusion, coronary vascular response to acetylcholine was examined. Solutions of acetylcholine (100 $\mu \mathrm{mol} / \mathrm{L}$; Sigma Chemical Company, St. Louis, Mo.) were freshly prepared for each experiment in filtered $(0.2 \mu \mathrm{m})$ Krebs-Henseleit buffer and infused into the aortic root for 1 minute at rates of 5,10 , and $20 \mathrm{nmol} / \mathrm{min}$; coronary perfusion pressure was allowed to return to baseline before infusion rate was increased.

Wet/dry weight ratio. Myocardial water content was measured as an index of tissue edema. Full-thickness sections of LV myocardium were gently blotted dry of excess perfusate, weighed, and then dried to constant weight in a $37^{\circ} \mathrm{C}$ oven. These values were expressed as the dry/wet weight ratio.

Statistical analysis. Data were expressed as mean values \pm standard error of the mean. Multiple group comparisons were made by analysis of variance for repeated measures with the Bonferroni procedure. Data analysis was performed with commercially available software (Statview and Super-Anova, Abacus Concepts, Berkeley, Calif.) in consultation with a statistician (Wayne DellaMaestra, BS). A $p$ value less than 0.05 was considered significant.

\section{Results}

Early reperfusion: Restoration of coronary flow was accompanied by ventricular fibrillation in six of six hearts preserved with UW solution and in three of six preserved with the highly buffered solution. UW-preserved hearts fibrillated two to five times (average three), whereas two of six buffer-preserved hearts did so only once (one of six fibrillated twice). LV end-diastolic pressure increased sharply in all hearts during reperfusion; after successful defibrillation, LV end-diastolic pressure was $9 \pm 4 \mathrm{~cm}$ $\mathrm{H}_{2} \mathrm{O}$ in hearts treated with highly buffered solution, as compared with $17 \pm 4 \mathrm{~cm} \mathrm{H}_{2} \mathrm{O}$ in UW-treated hearts $(p=0.06)$.

Systolic function. The effect of 20 hours of hypothermic $\left(4^{\circ} \mathrm{C}\right)$ preservation with a single dose of either UW 
solution or the highly buffered solution is shown in Fig. 1 . The buffered solution produced significantly greater recovery of $\mathrm{LV}$ developed pressure and $\mathrm{dP} / \mathrm{dt}$ than did UW solution. At 60 minutes of reperfusion in buffer-preserved hearts, values for these variables were not different from those observed in the control preparation. Recovery of systolic function was markedly impaired in UW-preserved neonatal hearts.

Diastolic function: Values of $-\mathrm{dP} / \mathrm{dt}$, and $\mathrm{dP} / \mathrm{dV}$ (chamber compliance) are shown in Fig. 2. The rate of relaxation as assessed by $-\mathrm{dP} / \mathrm{dt}$ was significantly impaired in both groups; however, recovery of $-\mathrm{dP} / \mathrm{dt}$ was greater in buffer-preserved hearts. The slope of the LV diastolic pressure-volume relationship at an enddiastolic pressure of 5 was decreased to a similar extent in both groups of hearts.

Oxidative metabolism. Myocardial oxygen consumption in hearts preserved with histidine-buffered solution recovered to approximately $68 \%$ of control values by 30 minutes of reperfusion; recovery was essentially complete by 60 minutes (Fig. 3). These improvements paralleled those seen in systolic function (Fig. 1). In stark contrast, myocardial oxygen consumption was significantly depressed in. UW hearts at 30 minutes and deteriorated somewhat further by 60 minutes. Control hearts extracted lactate in the amount of $210 \pm 26 \mathrm{nmol} / \mathrm{min}$ per gram. UW hearts demonstrated net lactate release of $412 \pm 78$ and $324 \pm 91 \mathrm{nmol} / \mathrm{min}$ per gram at 30 and 60 minutes of reperfusion, respectively. Lactate metabolism in buffer-preserved hearts was variable at 30 minutes of reperfusion, with two of six hearts extracting lactate and four of six demonstrating release; overall, there was net release of $121 \pm 55 \mathrm{nmol} / \mathrm{min}$ per gram. However, by 60 minutes of reperfusion, buffer-preserved hearts were characterized by net lactate extraction of $55 \pm 21 \mathrm{nmol} /$ min per gram.

Coronary tone. The effects of the different preservation solutions on basal coronary resistance and responses to acetylcholine are shown in Table I. Preservation with UW solution was characterized by increased basal coronary vascular resistance and a predominantly vasoconstrictor response to acetylcholine. In contrast, acetylcholine-induced vasodilation was preserved in buffer-treated hearts.

Tissue water accumulation: Dry/wet ratios were $18.5 \% \pm 0.1 \%$ in control hearts $17.9 \% \pm 0.5 \%$ in UW-preserved hearts, and $18.1 \% \pm 0.2 \%$ in buffer-preserved hearts. These differences were not significant.

\section{Discussion}

Numerous factors, including duration of ischemia, temperature, species, age, organ type, and preservation
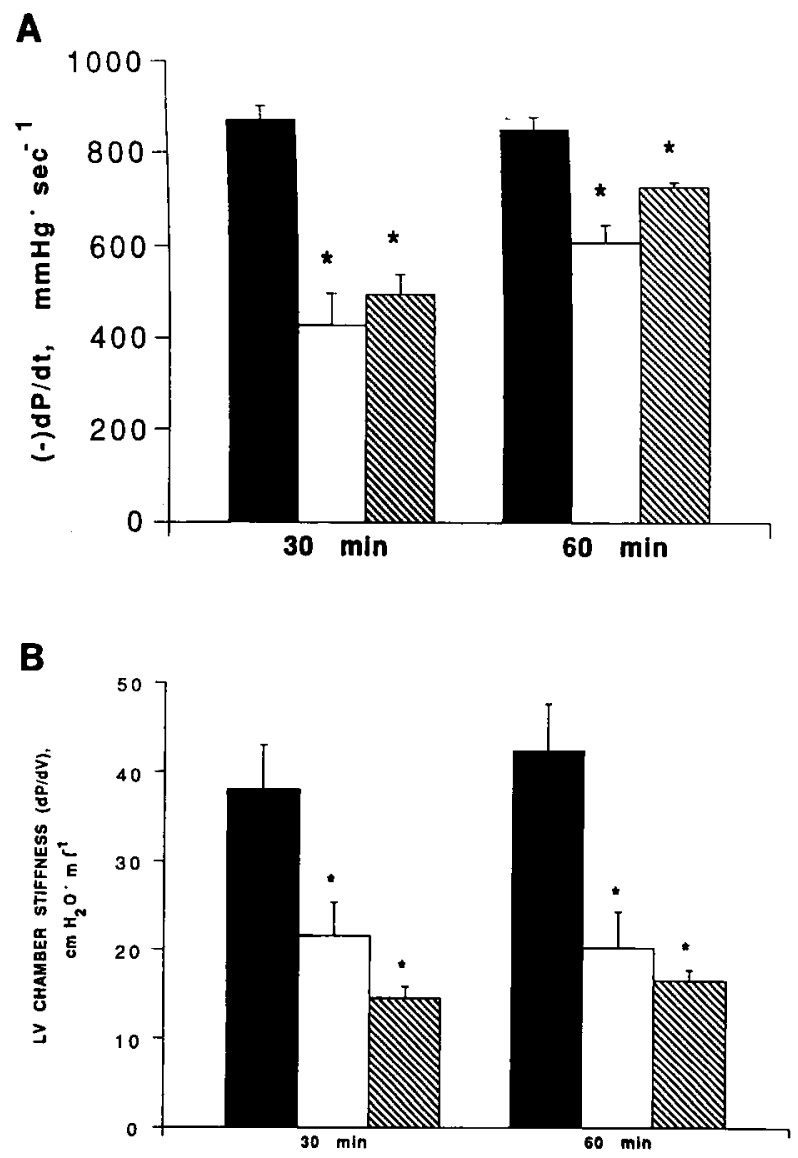

Fig. 2. Diastolic function in control hearts (solid bars) and after myocardial preservation with modified UW solution (open bars) and histidine-buffered solution (hatched bars). A, First derivative of $L V$ pressure decline $(-\mathrm{dP} / \mathrm{dt})$. B, LV chamber stiffness $(d P / d V)$ obtained from the slope of $\mathrm{LV}$ pressure-volume curves (see text). Values are mean \pm standard error of the mean. Times shown are during reperfusion. ${ }^{*} p<0.05$ versus control.

method, underly susceptibility to ischemia. In addition to these factors, reperfusion phenomena such as oxidant injury and calcium overload determine the final outcome of ischemia-reperfusion. ${ }^{34,35}$ With shorter durations of myocardial ischemia, it is likely that reperfusion injury, especially of the vasculature, is a critical determinant of outcome. In addition to mitigation of reperfusion injury, successful long-term myocardial preservation mandates optimal preservation of intracellular high-energy phosphates and the capacity for aerobic metabolism. In contrast to other types of crystalloid cardioplegic solutions, buffered cardioplegic solutions have been shown to maintain intracellular high-energy phosphates and intracellular and interstitial $\mathrm{pH}$, reduce myocardial necrosis, and 


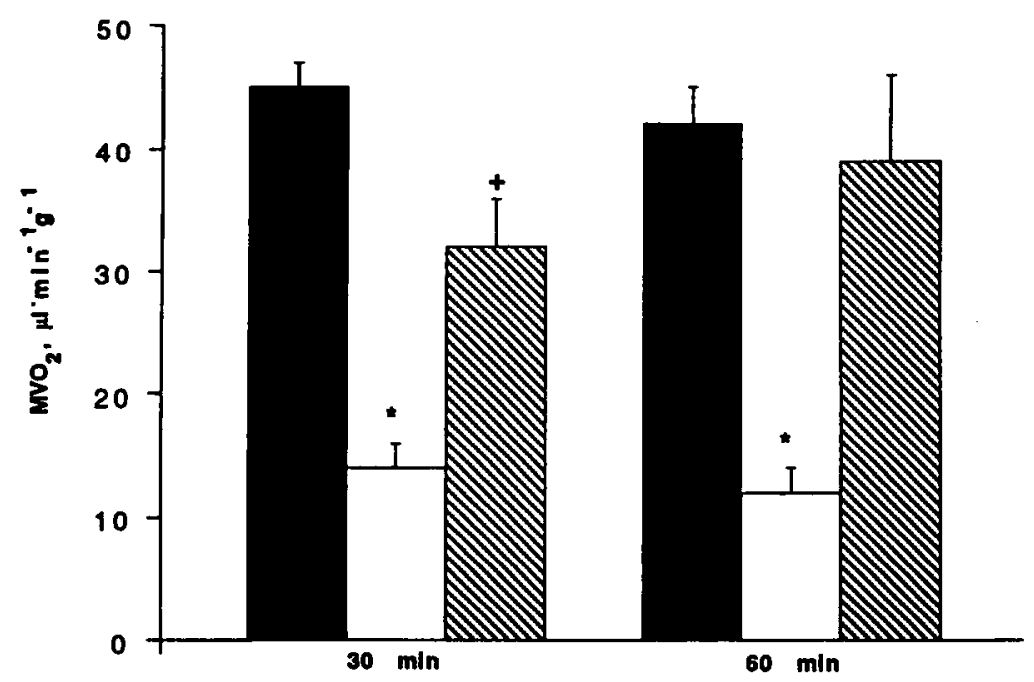

Fig. 3. Myocardial oxygen consumption $\left(\mathrm{MVO}_{2}\right)$ in control neonatal hearts (solid bar) and after hypothermic preservation with modified UW solution (open bar) and histidine-buffered solution (hatched bar). Values are mean \pm standard error of the mean. ${ }^{*} p<0.01$ versus control. ${ }^{+} p<0.05$ versus control.

Table I. Effect of neonatal myocardial preservation with UW solution or buffered solution on coronary perfusion pressure

\begin{tabular}{llllccc}
\hline & \multicolumn{2}{c}{$C P P(\mathrm{~mm} \mathrm{Hg})$} & & \multicolumn{2}{c}{$C P P(\%)$ change $)$} \\
\cline { 2 - 3 } \cline { 5 - 7 } & $30 \mathrm{~min}$ & $60 \mathrm{~min}$ & & ACh $1.0 \mathrm{nmol} / \mathrm{min}$ & Ach $10.0(\mathrm{nmol} / \mathrm{min})$ & ACh $20 \mathrm{nmol} / \mathrm{min}$ \\
\hline Control & $57 \pm 2$ & $59 \pm 2$ & & $-2.3 \pm 0.8$ & $-4.1 \pm 0.5$ & $-8.9 \pm 1.1$ \\
UW & $66 \pm 3^{*}$ & $69 \pm 3^{*}$ & & $+2.3 \pm 0.8^{*}$ & $+4.4 \pm 1.0$ & $+6.2 \pm 0.9 \dagger$ \\
Buffer & $54 \pm 3$ & $58 \pm 3$ & & $-3.1 \pm 0.3$ & $-4.3 \pm 0.4$ & $-5.2 \pm 0.9$. \\
\hline
\end{tabular}

Values are mean \pm standard error of the mean. $C P P$, Coronary perfusion pressure. $A C h$, acetylcholine.

${ }^{*} p<0.05$ compared with control or buffered solution.

$\dagger p<0.01$ compard with control or buffered solution.

promote improved postischemic contractile performance. ${ }^{28-30,36}$ The present study of neonatal pig hearts stored for 20 hours at $4^{\circ} \mathrm{C}$ demonstrated significant preservation of contractile function, oxidative metabolism, and vascular function by a solution containing significant buffering capacity supplied by histidine.

The maximal duration of storage for human heart transplants remains 4 to 6 hours. ${ }^{1-4}$ The development of UW solution has greatly extended the amount of time available for successful storage and transplantation of liver, kidney, and pancreas to 24 to 48 hours. ${ }^{37,} 38 \mathrm{UW}$ solution was formulated primarily to inhibit development of cellular edema during preservation and to promote rapid energy restoration and minimize free radical injury during reperfusion. Results of experimental cardiac preservation with UW solution have been shown to be superior to those obtained with modified Collins, Stanford, St. Thomas' Hospital, and Bretschneider solutions in a vari- ety of animal models, ${ }^{37}$ yet the efficacy of UW solution in the heart continues to be significantly less than in other organs.

On the basis of the components of UW solution (see Table II), one would predict that there would be little effect on ATP loss during ischemia beyond the effects of concomitant hypothermia to lower metabolic rate. Hearts preserved with UW solution maintained total myocardial ATP stores for several hours, but ATP concentration declined to approximately $80 \%$ of control by 12 hours and to $40 \%$ by 24 hours of cold storage. ${ }^{38}$ Ischemic contracture in these hearts began when ATP concentrations decreased to less than $80 \%$ of normal. Significant myocardial ATP depletion has been associated with swelling of the mitochondria and sarcoplasmic reticulum, depletion of glycogen granules, and, ultimately, formation of contraction bands and disruption of the cell membrane. $^{34,39}$ In UW-preserved liver and kidney, ATP 
decreased rapidly within the first hour of ischemia and reached approximately $10 \%$ of preischemic concentrations within 4 hours. ${ }^{38}$ However, this degree of ATP depletion in these organs does not appear to result in significant structural damage or irreversible injury.

The greater sensitivity of the heart to reductions in ATP during ischemia may be related to the presence of actin and myosin; decreasing myocyte ATP below a critical concentration results in the development of contracture. Although the precise cause of ischemic contracture remains controversial, most evidence suggests that rigor develops as a result of ATP deficiency at the myofibrils, which allows myosin-actin crossbridge formation. The critical ATP concentration needed for onset of rigor has been a subject of controversy. ${ }^{39-41}$ It is likely that the source of ATP to the myofibrils is more important than the absolute total intracellular concentration of ATP. Glycolysis or creatine kinase, or a combination of the two, may be most efficient in this regard ${ }^{42-44}$; onset of ischemic contracture has been correlated with cessation of anaerobic glycolytic ATP generation. ${ }^{45}$ Furthermore, use of exogenous glucose for anaerobic glycolysis during ischemia may be more protective than glucose derived from glycogen. ${ }^{46}$

It thus seems clear that measures to promote anaerobic glycolysis, especially of glucose, might be beneficial during prolonged ischemia. This may be especially true in the neonate because of increased myocardial glycolytic potential. ${ }^{12,13,19}$ During ischemia, anaerobic glycolysis is initially accelerated, leading to accumulation of $\mathrm{H}^{+}$and lactate that inhibit further glycolysis, mainly at glyceraldehyde-3-phosphate dehydrogenase. ${ }^{34}$ Cytosolic nicotinamide-adenine dinucleotide (reduced) which also inhibits glycolysis, accumulates as a result of failure of mitochondrial oxidation and impairment of the malateaspartate shuttle. As a result, anaerobic glycolytic activity decreases rapidly after the onset of total, global ischemia and is absent by 40 to 60 minutes in most preparations. ${ }^{34}$ Providing exogenous histidine, which gains rapid access to the intracellular space, will buffer intracellular protons. This will (1) decrease inhibition of anaerobic glycolysis and (2) maintain high-energy phosphates as charged species, thereby limiting diffusion out of the cell. Also, enhanced buffering in the extracellular space may facilitate intracellular-to-extracellular lactate and $\mathrm{H}^{+}$transport by the lactate $/ \mathrm{H}^{+}$co-transporter, which is inhibited by extracellular proton accumulation.

An interesting and unexpected result of this study was the beneficial effect of the buffering solution on coronary vascular resistance. Ischemia and reperfusion cause both functional and structural evidence of coronary vascular damage. ${ }^{47}$ Reactive species derived from oxygen and
Table II. Composition of cardioplegic solutions

\begin{tabular}{|c|c|c|}
\hline & $\begin{array}{l}\text { Buffered } \\
\text { solution }\end{array}$ & $\begin{array}{l}U W \\
\text { solution }\end{array}$ \\
\hline $\mathrm{Na}^{+}(\mathrm{mmol} / \mathrm{L})$ & 80.0 & 20.0 \\
\hline $\mathrm{K}^{+}(\mathrm{mmol} / \mathrm{L})$ & 22.5 & 140.0 \\
\hline $\mathrm{Mg}^{2+}(\mathrm{mmol} / \mathrm{L})$ & 6.0 & 5.0 \\
\hline $\mathrm{Ca}^{2+}(\mathrm{mmol} / \mathrm{L})$ & 0.1 & 0.0 \\
\hline $\mathrm{PO}_{4}{ }^{2-}(\mathrm{mmol} / \mathrm{L})$ & 2.5 & 25.0 \\
\hline Glucose (mmol/L) & 11.0 & 0.0 \\
\hline Insulin (IU/L) & 10.0 & 100.0 \\
\hline Mannitol (mmol/L) & 20.0 & 0.0 \\
\hline Histidine $\mathrm{HCI}(\mathrm{mmol} / \mathrm{L})$ & 100.0 & 0.0 \\
\hline Adenosine $(\mathrm{mmol} / \mathrm{L})$ & 5.0 & 5.0 \\
\hline Lidocaine (mg/L) & 100.0 & 0.0 \\
\hline Lactobionate $(\mathrm{mmol} / \mathrm{L})$ & 0.0 & 100.0 \\
\hline Raffinose (mmol/L) & 0.0 & 30.0 \\
\hline $\begin{array}{l}\text { Hydroxyethyl } \\
\text { starch }(\%)\end{array}$ & 0.0 & 5.0 \\
\hline Glutathione $(\mathrm{mmol} / \mathrm{L})$ & 0.0 & 3.0 \\
\hline Allopurinol $(\mathrm{mmol} / \mathrm{L})$ & 0.0 & 1.0 \\
\hline Heparin (IU/L) & 0.0 & 1000.0 \\
\hline $\mathrm{pH}$ & 7.8 & $7.2-7.3$ \\
\hline $\begin{array}{l}\text { Osmolarity } \\
\qquad(\mathrm{mOsm} / \mathrm{L})\end{array}$ & 340 & 300 \\
\hline
\end{tabular}

purine metabolism in both the tissue and invading leukocytes have been strongly implicated in its pathogenesis. ${ }^{47}$. 49 Microvascular damage may exacerbate myocyte reperfusion injury. ${ }^{50-52}$ Hypothermic potassium cardioplegia has recently been shown to impair endothelium-dependent coronary relaxation. ${ }^{53,54}$ Both free radical injury and depletion of critical high-energy substrates are likely to be important contributors to vascular injury in the setting of prolonged myocardial ischemia. It should be noted that leukocytes were absent from the model used for the present investigations.

The increase in baseline coronary vascular resistance in UW-preserved hearts may be indicative of impaired vasoregulation by coronary endothelium or smooth muscle, or both. Alternatively, because hearts were perfused at constant flow, the apparent increase in coronary vascular resistance in UW-preserved hearts may also reflect excessive coronary flow relative to reduced work and oxygen consumption. However, the fact that acetylcholine produced constriction in UW hearts and caused dilation in buffer-preserved hearts (which was similar to that seen in control hearts) strongly suggests that buffering protected against endothelial damage. Decreased coronary resistance due to acetylcholine is mediated, at least in part, by stimulating endothelial production of vasodilating substances such as prostacyclin and nitric oxide. Acetylcholine can cause vasoconstriction via smooth muscle contraction at high concentrations or 
when endothelial release of nitric oxide or prostacyclin is impaired. ${ }^{55,}{ }^{56}$ Although we did not attempt to determine the relative roles of prostanoids and nitric oxide in the present study, we have recently demonstrated that prostanoid compounds do not play a significant role in acetylcholine-induced coronary dilation in the piglet; rather, acetylcholine-induced coronary dilation is inhibited, and acetylcholine-induced constriction enhanced, by inhibitors of nitric oxide synthesis. ${ }^{57}$ Furthermore, in a model of global normothermic ischemia and reperfusion, constitutive nitric oxide production was not impaired, but coronary dilation resulting from agonists such as acetylcholine and bradykinin was significantly reduced. ${ }^{57}$ Therefore, we speculate that the buffered solution is effective at preserving either endothelial cell membrane receptors or subsequent signal transduction.

\section{REFERENCES}

1. Swanson DK, Myerowitz PD. Heart preservation for transplantation. In: Myerowitz PD, ed. Heart transplantation. Mount Kisco, NY: Futura, 1987:339-55.

2. Belzer FO, Southard JH. Principles of solid organ preservation by cold storage. Transplantation 1988;45:473-6.

3. English TAH, Spratt P, Wallwork J, Cory-Pearce R, Wheeldon D. Selection and procurement of hearts for transplantation. Br Med J 1984;288:1889-91.

4. Choong YS, Gavin JB. Functional recovery of hearts after cardioplegia and storage in University of Wisconsin and St. Thomas'. Hospital solutions. J Heart Lung Transplant 1991;10:537-46.

5. Pflugfelder PW, Thomson D, Singh NR, Menkis AH, McKenzie FN, Kostuk WJ. Cardiac ischemic time: relation to graft survival and cardiac function. Circulation 1989;80(Suppl):III116-21.

6. Qayumi AK, Jamieson WRE, Rosado LJ, et al. Preservation techniques for heart transplantation: comparison of hypothermic storage and hypothermic perfusion. $\mathbf{J}$ Heart Lung Transplant 1991;10:518-26.

7. Bull C, Cooper J, Stark J. Cardioplegic protection of the child's heart. J THORAC CARdiOvaSC SURG 1984;88:28793.

8. Kirklin J, Blackstone E, Kirklin J, McKay R, Pacifico A, Bargeron L. Intracardiac surgery in infants under age 3 months: incremental risk factors for hospital mortality. Am J Cardiol 1981;48:500-12.

9. Parrish MD, Payne A, Fixler DE. Global myocardial ischemia in the newborn, juvenile, and adult isovolumic rabbit heart: age-related differences in systolic function, diastolic stiffness, coronary resistance, myocardial oxygen consumption, and extracellular pH. Circ Res 1987;61:60915.

10. Yano Y, Braimbridge MV, Hearse DJ. Protection of the pediatric myocardium: differential susceptibility to ischemic injury of the neonatal rat heart. J THORAC CARDIOVASC SURG 1987;94:887-96.
11. Ascuitto RJ, Ross-Ascuitto NT, Chen V, Downing SE. Ventricular function and fatty acid metabolism in neonatal pig heart. Am J Physiol 1989;256:H9-15.

12. Wells RJ, Friedman WF, Sobel BE. Increased oxidative metabolism in the fetal and newborn lamb heart. Am J Physiol 1972;222:1488-93.

13. Fisher DJ. Oxygenation and metabolism in the developing heart. Sem Perinatol 1984;8:217-24.

14. Bers DM, Philipson KD, Langer GA. Cardiac contractility and sarcolemmal calcium binding in several cardiac muscle preparations. Am J Physiol 1981;240:H57683.

15. Friedman WF. The intrinsic physiologic properties of the developing heart. Prog Cardiovasc Dis 1972;15:87111.

16. Nayler WG, Fassold E. Calcium accumulation and ATPase activity of cardiac sarcoplasmic reticulum before and after birth. Cardiol Res 1977;11:231-7.

17. Chin TK, Friedman WF, Klitzner TF. Developmental changes in cardiac myocyte calcium regulation. Circ Res 1990;67:574-9.

18. Hoerter J, Mazet F, Vassart G. Perinatal growth of the rabbit cardiac cell: possible implications for the mechanism of relaxation. J Mol Cell Cardiol 1981;13:725-40.

19. Dawes GS, Mott JC, Shelley JJ. The importance of cardiac glycogen for the maintenance of life in fetal lambs and newborn animals during anoxia. J Physiol 1959;146:51628.

20. Wittnich C, Penniston C, Lanuzzo D, Abel JG, Salerno TA. Relative vulnerability of neonatal and adult hearts to ischemic injury. Circulation 1987;76(Suppl):V156-60.

21. Jarmakani JM, Nakazawa M, Nagamoto T, Langer GA. Effect of hypoxia on mechanical function in neonatal mammalian heart. Am J Physiol 1978;235:H474-94.

22. Nishioka K, Jarmakani JM. Effect of ischemia on mechanical function and high-energy phosphates in rabbit myocardium. Am J Physiol 1982;242:H1077-83.

23. Chiu RC-J, Bindon $W$. Why are newborn hearts vulnerable to ischemia? The lactate hypothesis. Circulation 1987;76(Suppl):V146-9.

24. Coles JG, Watanabe T, Wilson GJ, et al. Age-related differences in the response to myocardial ischemic stress. $J$ Thorac Cardiovasc Surg 1987;94:526-34.

25. Avkiran M, Hearse DJ. Protection of the myocardium during global ischemia. Is crystalloid cardioplegia effective in the immature myocardium? J THORAC CARDIOVASC SURG 1989;97:220-8.

26. Hammon JW, Graham TP Jr, Boucek RJ, Parrish MD, Merrill WH, Bender HW Jr. Myocardial adenosine triphosphate content as a measure of metabolic and functional myocardial protection in children undergoing cardiac operation. Ann Thorac Surg 1987;44:467-70.

27. Magovern JA, Pae WE Jr, Miller CA, Waldhausen JA. The immature and the mature myocardium: responses to multidose crystalloid cardioplegia. J THORAC CARDIOVASC SURG 1988;95:618-24.

28. del Nido PJ, Wilson JG, Mickle DAG. The role of 
cardioplegic solution buffering in myocardial protection. $\mathrm{J}$ Thorac Cardiovasc Surg 1985;89:689-99.

29. Ohkado A, Cao-Danh HM, Sommers KE, del Nido PJ. Twenty-four hour myocardial preservation with cardioplegic buffering. Surg Forum 1992;51:319-21.

30. Ohkado A, Cao-Danh H, Sommers KE, del Nido PJ. Evaluation of highly buffered low-calcium solution for long-term preservation of the heart: comparison with University of Wisconsin solution. J THORAC CARDIOvaSC SURG 1994;108:762-71.

31. McGowan FX, Lee FA, Chen V, Downing SE. Oxidative metabolism and mechanical function in reperfused neonatal pig heart. J Mol Cell Cardiol 1992;24:831-40.

32. Glantz SA, Parmley WW. Factors which affect the diastolic pressure-volume curve. Circ Res 1978;42:171-86.

33. Lowry $\mathrm{OH}$, Passoneau JV. A flexible system of enzyme analysis. New York: Academic Press, 1972:151-4.

34. Jennings RB, Murry CE, Steenbergen C Jr, Reimer KA. Development of acute injury in sustained acute ischemia. Circulation 1990;82(Suppl):II2-12.

35. Bolli R. Mechanism of myocardial stunning. Circulation 1990;82:723-38.

36. Tait GA, Booker PD, Wilson GJ, Coles JG, Steward DJ, MacGregor DC. Effect of multidose cardioplegia and cardioplegic buffering on myocardial tissue acidosis. J THORAC Cardiovasc SuRg 1982;83:824-9.

37. D'Alessandro AM, Kalayoglu M, Sollinger $\mathrm{HW}$, et al. Current status of organ preservation with University of Wisconsin solution. Arch Pathol Lab Med 1991;115:30614.

38. Stringham JC, Southard JH, Hegge J, Triemstra L, Fields BL, Belzer FO. Limitations of heart preservation by cold storage. Transplantation 1992;53:287-94.

39. Jennings RB, Hawkins HK, Lowe JE, Hill ML, Klotman S. Relation between high energy phosphate and lethal injury in myocardial ischemia in the dog. Am J Pathol 1978; 92:187-207.

40. Steenbergen C, Murphy E, Watts JA, London RE. Correlation between cytosolic free calcium, contracture, ATP, and irreversible ischemic injury in perfused rat heart. Circ Res 1990;66:135-46.

41. Humphrey SM, Holliss DG, Seelye RN. Adenine pool catabolism in the ischemic, the calcium-depleted ischemic, and the substrate-free anoxic isolated rat heart: relationship to contracture development. J Mol Cell Cardiol 1984; 16:1127-36.

42. Ventura-Clapier R, Mekhfi H, Vassort G. Role of creatine kinase in force development in chemically skinned rat cardiac muscle. J Gen Physiol 1987;89:815-37.

43. Bricknell OL, Daries PS, Opie LH. A relationship between adenosine triphosphate, glycolysis, and ischemic contracture in the isolated rat heart. J Mol Cell Cardiol 1981; 13:941-5.

44. Haworth RA, Nicolaus A, Goknur AB, Berkoff HAं. Synchronous depletion of ATP in isolated adult rat heart cells. J Mol Cell Cardiol 1988;20:837-46.

45. Kingsley PB, Sako EY, Yang MQ, et al. Ischemic contracture begins when anaerobic glycolysis stops: a ${ }^{31} \mathrm{P}-\mathrm{NMR}$ study of isolated rat hearts. Am J Physiol 1991;261:H46978.

46. Owen P, Dennis S, Opie LH. Glucose flux rate regulates onset of ischemic contracture in globally underperfused rat hearts. Circ Res 1990;66:344-54.

47. Forman MB, Puett DW, Virmani R. Endothelial and myocardial injury during ischemia and reperfusion: pathogenesis and therapeutic implications. J Am Coll Cardiol 1989;13:450-9.

48. Sunnergren KP, Rovetto MJ. Myocyte and endothelial injury with ischemia-reperfusion in isolated rat hearts. Am J Physiol 1987;252:H1211-7.

49. Dauber IM, Lesnefsky EJ, VanBenthuysen KM, Weil JV, Horowitz LD. Reactive oxygen metabolite scavengers decrease functional coronary microvascular injury due to ischemia-reperfusion. Am J Physiol 1991;260:H42-9.

50. Quillen JE, Selke FW, Brooks LA, Harrison DG. Ischemia-reperfusion impairs endothelium-dependent relaxation of coronary microvessels but does not affect large arteries. Circulation 1990;82:586-94.

51. Lefer AM, Tsao PS, Lefer DJ, Ma X-L. Role of endothelial dysfunction in the pathogenesis of reperfusion injury after myocardial ischemia. FASEB J 1991;5:2029-34.

52. Hashimoto K, Pearson PJ, Schaff HV, Cartier R. Endothelial cell dysfunction after ischemia arrest and reperfusion: a possible mechanism of myocardial injury during reflow. J THORAC CARDIOVASC SURG 1991;102:688-94.

53. Sellke F, Shafique T, Schoen F, Weintraub R. Impaired endothelium-dependent coronary microvascular relaxation after cold potassium cardioplegia and reperfusion. $\mathbf{J}$ THORAC Cardiovasc Surg 1993;105:52-8.

54. Cartier R, Pellerin M, Hollmann C, Pelletier L. Effects of pressure and duration of hyperkalemic infusions on endothelial function. Ann Thorac Surg 1993;55:700-5.

55. Luscher TF, Richard V, Tschudi M, Yang Z, Boulanger C. Endothelial control of vascular tone in large and small coronary arteries. J Am Coll Cardiol 1990;15:519-27.

56. Moncada S. The L-arginine:nitric oxide pathway. Acta Physiol Scand 1992;145:201-27.

57. McGowan FX, Davis PJ, del Nido PJ, Sobek M, Allen JW, Downing SE. Endothelium-dependent regulation of coronary tone in the neonate. Anesth Analg [In press] 